\title{
A PRÁTICA DO TRATAMENTO NA LEISHMANIOSE VISCERAL CANINA (LVC) EM CLÍNICAS VETERINÁRIAS, CUIDADOS E PROTOCOLOS
}

\author{
Ana Luísa Holanda de Albuquerque ${ }^{1}$ \\ Helio Langoni ${ }^{2}$
}

\section{RESUMO}

As leishmanioses são um grupo de doenças infecciosas que afetam humanos, animais domésticos (cães e gatos) e silvestres, causadas por protozoários do gênero Leishmania. A transmissão ocorre pela picada do mosquito do gênero Phlebotomus no Velho Mundo e Lutzomyia no Novo Mundo. A Leishmaniose Visceral Canina (LVC), a forma mais agressiva, é causa frequente de doença clínica em cães e, ocasionalmente em gatos. Seus reservatórios variam de acordo com a região, podendo ser animais domésticos ou silvestres. Leishmania infantum está presente do sul do México até a América do Sul. No caso da LVC, a recomendação do Conselho Federal de Medicina Veterinária é a eutanásia. O tratamento era considerado ilegal até 2013, quando houve autorização do tratamento pelo Tribunal Regional Federal da $3^{\text {a }}$ Região em todo País, desde que não se utilizassem medicamentos para o tratamento da leishmaniose humana. Tratar ou não, indicar ou não eutanásia é questão polêmica para os clínicos veterinários, pois o tratamento não elimina totalmente a carga parasitária dos animais, e trata-se de uma zoonose. Em Brasília, a leishmaniose visceral é considerada endêmica, considerando o comportamento epidemiológico e a confirmação da autoctonia dos casos humanos. No presente estudo, foi aplicado questionário para se avaliar a prática do tratamento dessa enfermidade, em clínicas veterinárias de pequenos animais de Brasília. Cinco delas realizam o tratamento da LVC. Todas recomendam o alopurinol, quatro a miltefosina, três a marbofloxacina e duas a anfotericina B e antimoniais pentavalentes. Duas clínicas se recusaram a responder o questionário, e outras duas não realizam o tratamento, recomendando eutanásia.

Palavras-chave: LVC, tratamento, clínicas particulares, Brasília.

\begin{abstract}
The leishmaniasis are a group of infectious diseases that affect humans, dogs, cats and wild animals worldwide. It is caused by protozoa of the genus Leishmania. The infection is transmitted by sandflies of the genus Phlebotomus in the Old World and Lutzomyia in the New World. The Canine Visceral Leishmaniasis (CVL), the most severe disease form, is a frequent cause of clinical illness in dogs depending on the region, being less common in cats. The Brazilian Federal Counsel of Veterinary Medicine recommendation for the CVL illness is euthanasia, being illegal to treat until 2013, when the Third Region Federal Court authorized it all over the Country, as long as the medication isn't the same used in humans. Whether to treat or not and sacrifice the animal is a polemic veterinary issue, since the treatment does not eliminate the entire parasite load, and it is a zoonosis. In Brasilia, Visceral Leishmaniasis is endemic, considering its epidemiological behavior and the confirmation of autochthony of human cases. In this study, small animal veterinarians were questioned about the treatment of Canine Visceral Leishmaniosis in Brasilia, DF, Brazil to evaluate the treatment practice of the CVL. Five out of nine do the treatment. All of the clinicians use alupurinol, four use miltefosin, three of them use marbofloxacin, two use pentavalents antimonial and anfotericin
\end{abstract}

\footnotetext{
${ }^{1}$ Médica Veterinária Residente da Clínica de Grandes Animais da FMVZ UNESP Botucatu.

${ }^{2}$ Professor Titular do Departamento de Higiene Veterinária e Saúde Pública - FMVZ-UNESP-Botucatu.
} 
B. However, two veterinary clinics do not treat and recommend euthanasia, two clinics didn't want to discuss their protocol.

Keywords: CVL, treatment, small animal clinics, Brasilia, Brazil.

\section{LA PRÁCTICA DEL TRATAMIENTO EN NA LEISHMANIOSIS VISCERAL CANINA (LVC) EN CLÍNICAS VETERINÁRIAS, CUIDADOS Y PROTOCOLOS}

\section{RESUMEN}

La leishmaniasis son un grupo de enfermedades infecciosas que afectan a los seres humanos, animales domésticos (perros y gatos) y salvajes causadas por protozoos del género Leishmania. La transmisión se produce a través de la picadura del mosquito género Phlebotomus en el Viejo Mundo, y Lutzomyia en el Nuevo Mundo. La Leishmaniasis Visceral Canina (LVC), es la causa más agresiva, y más frecuente de la enfermedad clínica en perros, y gatos de vez en cuando. Sus depósitos varían según la región y pueden ser animales domésticos o salvajes. Leishmania (leishmania) infantum está presente en el sur de México hasta América del Sur. En el caso de la LVC, la recomendación del Consejo Federal de Medicina Veterinaria es la eutanasia y el tratamiento se consideraba ilegal hasta 2013, cuando se produjo la autorización del tratamiento por el Tribunal Regional $3^{\mathrm{a}}$ Región Federal en todo el país, desde que no se utilizan fármacos para el tratamiento de la leishmaniasis humana. Tratar o no, indicar o no la eutanasia es tema polémico para los veterinarios porque el tratamiento no elimina totalmente la carga parasitaria de los animales, y es una zoonosis. En Brasilia, la leishmaniasis visceral se considera endémica, teniendo en cuenta el comportamiento epidemiológico y la confirmación de los casos humanos autóctonos. En este estudio, se aplicó un cuestionario para evaluar la práctica del tratamiento de esta enfermedad en nueve clínicas veterinarias para pequeños animales en Brasilia. Cinco clínicas realizán el tratamiento de LVC. Todas recomiendan alopurinol, cuatro miltefosina, tres marbofloxacinam, dos anfotericina B y antimonio pentavalente. Dos clínicas se negaron a contestar el cuestionario, y dos no realizaron el tratamiento, recomendando la eutanasia.

Palabras clave: LVC, tratamiento, clínicas veterinarias para pequeños animales, Brasilia, Brasil.

\section{INTRODUÇÃO}

A leishmaniose na sua forma visceral é uma zoonose causada por protozoário. Além do ser humano, os cães e outros animais são acometidos. Nos últimos anos tem se observado um aumento do número de casos positivos da doença bem como uma maior preocupação das autoridades de saúde pública. Esta doença, pela sua gravidade, adquiriu maior importância, sendo considerada como de notificação compulsória e um importante problema em saúde pública. A Leishmaniose Visceral Canina (LVC) é causada por protozoário do gênero Leishmania que em seu ciclo apresenta formas amastigotas, com flagelo interno e cinetoplasto visível, com forma de bastão e as formas promastigotas com flagelos longos que vivem no trato digestivo do inseto vetor (1).

Os reservatórios principais do agente são os roedores e os cães; humanos e gatos são provavelmente hospedeiros acidentais (2). O seu agente é Leishmania chagasi no novo mundo, e no velho mundo Leishmania donovani. L. chagasi é considerada sinônimo de $L$. infantum baseado em análises genéticas (3), sendo a forma mais encontrada no velho mundo. 
A transmissão para o vertebrado ocorre pela picada de insetos dípteros pertencentes à família Psychodidae e subfamília Phlebotominae, encontrados nas regiões tropicais, especialmente nas regiões quentes e úmidas do planeta. No Brasil, o principal gênero é Lutzomyia, com ampla distribuição, desde regiões do sul até o norte do país, sendo a espécie mais importante L. longipalpis (4). A transmissão pode ocorrer ainda por brigas, agulhas compartilhadas, por transfusões sanguíneas, acasalamentos e transmissão congênita $(5,6)$, entretanto, a transmissão vetorial é a mais importante, epidemiologicamente, a partir de formas prosmatigotas que se desenvolvem no flebotomíneo e são inoculadas no hospedeiro vertebrado quando o inseto se alimenta. Estas são fagocitadas pelos macrófagos e se disseminam pelo organismo do hospedeiro, na forma amastigota. Após um período de incubação de meses a anos, aparecem os sintomas (3).

As alterações mais frequentes em cães são esplenomegalia, linfadenopatia, alopecia, febre, rinite, dermatite, aumento dos ruídos pulmonares, icterícia, articulações doloridas e inchadas, uveíte e conjuntivite. As lesões cutâneas são caracterizadas por hiperqueratose, descamação e espessamento da pele. Ocorrem ainda perda de peso, poliúria, polidipsia, vômito, diarreia, epistaxis, petéquias, melena e, em ao redor de $30 \%$ dos casos, onicogrifose $(2,7)$. Algumas vezes cães infectados têm aparência normal, mas apresentam elevada carga parasitária na pele sadia e em órgãos (7), aspecto relevante para a saúde pública, na medida em que esses animais são fontes de infecção importantes na disseminação da LVC, devido ao repasto sanguíneo dos flebotomíneos, vetores transmissores da doença.

Alguns testes sorológicos para diagnóstico estão disponíveis, mas os recomendados atualmente pelo Ministério da Saúde são o DPP, que é um teste imunocromatográfico que utiliza o antígeno recombinante rK39, produzido pelo Laboratório Biomanguinhos. É disponibilizado na forma de kit, de fácil utilização, com resultado em 10 a 15 minutos, podendo-se utilizar o sangue, soro ou plasma do animal suspeito. O DPP é recomendado para triagem e como confirmatório, recomenda-se o teste imunoienzimático de ELISA, também comercializado pela Biomanguinhos. Este também utiliza o antígeno rK39, fato que melhora a sensibilidade dos testes (8). Alguns laboratórios utilizam a reação de imununofluorescência indireta (RIFI), bem como outros capazes de detectar a presença de anticorpos ou o próprio agente (9).

No diagnóstico parasitológico, o parasito pode ser demonstrado em material obtido de punção de medula óssea, linfonodos e de baço, em imprints ou esfregaços corados com corantes básicos, tais como Giemsa, Wright e Panótico (9). É possível ainda o diagnóstico molecular a partir da Reação em Cadeia pela Polimerase-PCR, para a pesquisa do DNA do parasita, com elevada sensibilidade, utilizando-se primers gênero e espécie-específicos (10).

Os aspectos ambientais contribuem para a ocorrência da LVC e as condições socioeconômicas precárias, tais como moradia e o saneamento que favorecem a multiplicação e manutenção do vetor uma vez que eles encontram animais para o repasto sanguíneo. Devem ser considerados os aspectos nutricionais que podem reduzir a resistência imunológica dos humanos, sendo a baixa imunidade um fator importante para a manifestação da doença (11).

A sua ocorrência é muito ampla no país, com notificação de casos em mais de 1.600 municípios onde ocorre autoctonia, em praticamente todos os estados da federação. Ocorreu de fato a urbanização da LVC, que era considerada predominantemente como doença de ambientes rurais e periurbanos, entretanto, ocorre em grandes centros urbanos como Rio de Janeiro, Belo Horizonte, Três Lagoas, Araçatuba, Bauru, entre outros (4).

A prevalência da LVC é elevada entre os cães do DF, sendo maior nos animais errantes (51\%), e nos cães domiciliados (49\%), em relação aos pertencentes a canis (24\%) (12). Em Brasília, a leishmaniose visceral é considerada endêmica, considerando-se o comportamento epidemiológico descrito e a confirmação da autoctonia de casos humanos (13). 
O tratamento da LVC é um tema bastante controverso, e a partir de 2008 passou a ser proibido no Brasil, por meio da Portaria Interministerial $\mathrm{n}^{\circ} 1.426$, e em 2009 o II Fórum de discussão sobre o assunto, realizado em Brasília, concluiu que o tratamento canino constitui em risco para a saúde pública, pois contribui para a disseminação da enfermidade, mantêm cães como reservatórios do parasito, há desenvolvimento de resistência de parasitos aos poucos medicamentos disponíveis para o tratamento da LV humana e dificulta a implementação de medidas de saúde pública (1).

As justificativas para a proibição da indicação de medicamentos utilizados para o tratamento de seres humanos com LV, para a terapia de cães infectados parte do princípio de que o tratamento da LVC traz riscos para a saúde pública, pela manutenção dos reservatórios da doença, uma vez que cães não curados parasitologicamente apresentam a remissão dos sinais clínicos, porém permanecem como fontes de infecção para o inseto transmissor, e consequentemente, perpetuam o ciclo de transmissão da doença. Destaque-se, ainda, que o tratamento da LVC poderá levar à seleção de estirpes de parasitos resistentes aos medicamentos disponíveis para o tratamento da LV humana (11).

Considerando que a prática de eutanásia de cães com diagnóstico de LVC não contribuiu para o controle da enfermidade, os profissionais médicos veterinários tentam buscar uma solução para os seus pacientes, atendendo na maioria das vezes uma cobrança dos proprietários dos animais que querem solucionar o problema, sem entretanto, eutanasiar seu animal de estimação. Dessa forma há clínicas que optam por tratamentos alternativos, com utilização de outros medicamentos que não são utilizados no tratamento realizado para a leishmaniose visceral humana.

$\mathrm{O}$ antimônio pentavalente foi o primeiro fármaco de escolha para tratamento, canino e humano, de leishmaniose visceral (3). A combinação de antimônio e alopurinol mostrou um resultado superior ao tratamento realizado com outro fármaco isolado (14). O tratamento de dois grupos de cães, um somente com o antimoniato de meglumina, e o outro com a associação do antimoniato de meglumina e alopurinol, revelou que, no primeiro grupo, todos os animais apresentaram recidivas em um período que variou de 4,5 a 21 meses, com 86\% delas ocorrendo dentro dos primeiros 14 meses, enquanto no grupo tratado com a associação dos dois medicamentos nenhum dos cães apresentou recidivas da doença (15).

A utilização do antimoniato de meglumina, durante 30 dias, em associação com alopurinol, durante seis meses, em 15 cães naturalmente infectados por Leishmania infantum, apesar da evidencia de exame citológico de medula óssea negativo mostrou positividade em sete cães, por PCR (16). A anfotericina B, um antibiótico polienico primariamente utilizado como antifúngico, também apresenta atividade contra alguns protozoários (3). A anfotericina $\mathrm{B}$ não é superior ao Alopurinol, e é mais cara e mais tóxica (17). Animais submetidos à terapia com esse medicamento mostram sinais de nefrotoxicidade causada pela vasoconstricção e posterior diminuição do fluxo sanguíneo renal. Anfotericina B lipossomal ou emulsificada em lípides em doses variadas tem sido prescrita, com bons resultados clínicos, entretanto, pode também ocorrer recidiva $(18,19)$.

De acordo com o estudo realizado por Nogueira (20), o efeito leishmanicida da terapia com anfotericina B associada ao alopurinol e prednisona foi comprovado pela ausência de parasitos no exame citopatológico de aspirado de linfonodo e por imunoistoquímica. A função das enzimas hepáticas ALT e AST não demonstrou alterações estatisticamente significativas durante o tratamento. $\mathrm{O}$ aumento significativo e progressivo das concentrações séricas de creatinina e uréia ocorreu após o início do tratamento, restabelecendo a normalidade posteriormente.

A formulação de antimônio lipossomal contendo fosfatidilserina demonstrou elevada eficácia in vivo, reduzindo 133 vezes a dose total de antimônio administrada, com diminuição de $100 \%$ da carga parasitária no fígado na dose de $0,75 \mathrm{mg} / \mathrm{kg}$ (21). Há resistência do 
protozoário a antimônios pentavalentes em áreas endêmicas como França, Espanha e Itália. Os dois principais medicamentos nessa classe são: estibogluconato de sódio, que requer injeção diária e apresenta vários efeitos adversos, e antimoniato de meglumina, que também tem menos efeitos colaterais (17).

A marbofloxacina foi eficaz in vitro e pode ser considerada para o tratamento de cães infectados se não houver outras opções disponíveis (22). Outros medicamentos estão sendo investigados para o tratamento da leishmaniose visceral canina, inclusive derivados de alquilfosfolcolina relacionado à miltefosina, que é utilizada em alguns tratamentos humanos para a leishmaniose visceral e metronidazol (3). A paramomicina tem mostrado ter menos efeitos colaterais do que outras substâncias em humanos. O seu uso tem sido primariamente indicado nas formas cutâneas de leishmaniose humana (17).

A imunomodulação adquirida em cães mediante a administração de $1 \mathrm{mg}$ por kg de peso vivo, a cada 12 horas durante um mês de domperidona oral em casos iniciais de LVC é efetiva para conter a evolução de enfermidade. A administração deste fármaco na mesma dose em cães com enfermidade avançada consegue melhorar os sintomas e em muitos casos mudar a resposta imune de Th2 a Th1 (23).

O ciprofloxacino a $0,2 \%$ se mostrou efetivo quando aplicado como solução salina hipertônica na leishmaniose no tratamento intralesional de casos de leishmaniose (24). A utilização de glicocorticóides no tratamento da LVC visa deprimir a imunidade humoral e, consequentemente, reduzir os efeitos causados pelo depósito de imunocomplexos nos órgãos e tecidos, particularmente em animais com insuficiência renal (14,25). Há estudos com a utilização de peptídeos antimicrobianos como agentes anti-protozoários. Com destaque para os Bombinins, Temporins, Phylloseptins e Decoralins (26).

Ainda, na busca de novos compostos com atividade leishmanicida, destacam-se os alcaloides, os acetogeninas, flavonóides e componentes de óleos essenciais. Foram utilizados alcalóides e acetogeninas extraídos da semente da Annona muricata (graviola); rutina e quercetina isolados das sementes Dimorphandra gardneriana (faveira), o eugenol, timol e seus derivados sintéticos, além da cumarina isolada do caule e cerne de Platymiscium floribundum (sacambu). A cumarina escoparona, e os flavonóides rutina e quercetina inibiram a enzima $\mathrm{AChE}$, indicando um possível mecanismo de ação para a atividade leishmanicida (27).

Verificou-se, também, efetiva atividade anti-Leishmania da secreção cutânea do caramujo gigante Africano, Achatina fulica, bem como a sua citotoxicidade em células de mamíferos e seu possível mecanismo de ação contra as formas promastigotas. A secreção bruta apresentou concentração efetiva $50 \%$ de $98,37 \mu \mathrm{g} / \mathrm{mL}$ contra promastigotas de $L .(L$.) chagasi. Por meio de ensaios enzimáticos, foi detectada a atividade L-aminoácido oxidase (LAAO) na secreção bruta, e também foi demonstrado que o $\mathrm{H} 2 \mathrm{O} 2$ gerado por esta enzima é um dos compostos responsáveis pelo efeito anti-leishmania (28).

A redução do parasitismo cutâneo, a eliminação das manifestações clínicas, e principalmente, a recuperação da resposta imune celular controladora da infecção poderiam levar a uma redução da capacidade infectante dos flebotomíneos e, consequentemente, a uma redução da prevalência nas espécies canina e humana, principalmente em áreas endêmicas (29), entretanto, apesar de inúmeras pesquisas, até o momento não há medicamentos profiláticos ou vacinas efetivas contra a leishmaniose. Medidas para proteger os cães incluem manter os animais dentro do domicílio, no período de maior atividade do vetor, o uso de repelentes e inseticidas. Coleiras impregnadas com repelentes também são efetivas para evitar que cães sejam picados por vetores (30,31).

Considerando-se a importância do controle da LVC, e os aspectos controversos com relação ao tratamento da enfermidade, o presente trabalho procurou conhecer a realidade da adoção de seu tratamento em cães com LVC em clínicas localizadas em Brasília, DF. 


\section{MATERIAIS E MÉTODOS}

Aplicou-se questionário com dez perguntas para obtenção de informações, enviado por e-mail para cada veterinário responsável por sua clínica na cidade de Brasília (Asa Sul, Asa Norte, Lago Sul e Lago Norte), contendo perguntas sobre o número de casos atendidos na clínicas, provas diagnósticas realizadas, em caso de opção de tratamento, qual foi preconizado, medidas preventivas, utilização de imunoprofilaxia, critérios de escolha dos proprietários de acordo com nível sócio-econômico, grau de comprometimento (responsabilidade), e com relação ao acompanhamento dos animais durante o tratamento, incluindo consultas e exames realizados (Anexo 1).

Há aproximadamente 40 clínicas veterinárias de pequenos animais, de diversas especialidades, em Brasília. Somente nove clínicas responderam ao e-mail. Duas delas declararam que não iriam responder, duas não realizam o tratamento e cinco clínicas atenderam o pedido. Havia um link disponível em <https://pt.surveymonkey.com/s/BX6NZBN>, criado pelo site Survey Monkey, que foi enviado para o e-mail de cada veterinário, de maneira que as respostas eram anônimas, sem possibilidade de identificação do participante da pesquisa.

\section{RESULTADOS E DISCUSSÃO}

A casuística atendida nas sete clínicas (cinco realizam tratamento e duas não realizam) é de, 350 animais com diagnóstico positivo de LVC em 2015. Sendo que a maioria, 187 (53, $42 \%$ ), não recebeu tratamento e foram submetidos a eutanásia de acordo com a Portaria Interministerial $\mathrm{n}^{\circ} 1.426$ (1). Já os outros $163(46,57 \%)$ animais que receberam tratamento, $109(66,9 \%)$ apresentaram resposta favorável e $54(33,13 \%)$ não responderam e foram submetidos a eutanásia.

Todas as clínicas utilizam o teste imunoenzimático ELISA como método diagnóstico, sendo este o teste sorológico confirmatório recomendado pela Vigilância das Doenças Transmissíveis do Ministério da Saúde (32). São utilizados ainda, a RIFI e a punção aspirativa de linfonodos ou de medula óssea. A PCR é utilizada por cinco clínicas. Três clínicas utilizam citologia e exame histopatológico e, outras duas, a impressão por aposição ou biópsia de lesões cutâneas ou gânglios linfáticos. Verifica-se que apesar do número de clínicas em que, voluntariamente, os veterinários responderam o questionário, mostrando interesse em participar da pesquisa, há conhecimento adequado e prática de diagnóstico laboratorial para confirmação da LVC, pois em $100 \%$ dos casos foi utilizado o teste de ELISA rK 39 que é recomendado como confirmatório (8), além de conhecer outras ferramentas diagnósticas

Algumas clínicas foram relutantes para discutir abertamente o tratamento da LVC, ou então, preferem não realizar o tratamento. Porém, nas cinco clínicas participantes, foram utilizados para o tratamento específico, além de tratamento suporte: miltefosina, marbofloxacina, alopurinol, anfotericina B, antimoniais pentavalentes (antomoniato de nmetil-glucamina ou estibogluconato de sódio), ciprofloxacino, cimetidina, doxiciclina, omeprazol, ranitidina, amitriptilina e domperidona.

$\mathrm{O}$ alopurinol foi utilizado em todas as clínicas, miltefosina em quatro, anfotericina $\mathrm{B}$ e antimoniais pentavalentes em duas; ciprofloxacino, amitriptilina, doxiciclina e domperidona somente em uma clínica. Verifica-se que os protocolos de tratamento são variados e por vezes sem base científica. Em desacato a orientação atual, quatro clínicas utilizam anfotericina B e antimoniais pentavalentes, medicamentos que são recomendados para o tratamento da leishmaniose humana $(1,11)$. 
Todas as clínicas preconizam vacinação de animais como medida preventiva. Cinco delas recomendam Leish-tec ${ }^{\circledR}$ e duas Leishmune ${ }^{\circledR}$. Da mesma forma todas preconizam a utilização de coleira repelente de deltametrina, seis a pulverização com inseticidas e duas recomendam a telagem de janelas. Há uma preocupação com relação à profilaxia da LVC e acredita-se que estas são condutas corretas e adequadas, que devem sempre estar associadas para que os resultados sejam favoráveis. Outra proposta relevante é a prática da guarda responsável e do bem estar animal, o que contribui também para melhor resposta do animal.

Enfatiza-se que apesar da proibição de medicamentos de uso humano no tratamento da leishmaniose como o glucantime e a anfotericina $\mathrm{B}$, algumas clínicas têm preconizado o uso destes, contrariando a portaria interministerial. Essa conduta deve ser evitada pois além de, sabidamente, não promoverem a cura com eliminação total do agente, e tão somente diminuição de carga parasitária, pode haver a seleção de resistência do agente (11), fato que pode complicar a resposta no tratamento humano, no futuro.

Para realizar o tratamento, as cinco clínicas fazem a seleção prévia de acordo com responsabilidade e comprometimento do proprietário. Quatro clínicas selecionam os casos para tratamento de acordo com o nível socioeconômico do proprietário. O grau de comprometimento dos responsáveis pelos animais é de extrema importância pois muitos cuidados devem ser observados, além do simples oferecimento de medicação diária. Por outro lado, é necessário estabelecer critérios com relação aos animais a serem tratados, por exemplo seu estado geral, grau e gravidade das lesões cutâneas, se há comprometimento renal a partir de exames como uréia e creatinina, entre outros parâmetros. O médico veterinário deve estar consciente sobre todos esses aspectos ao optar pelo tratamento dos animais.

As cinco clínicas que realizam tratamento fazem acompanhamento dos animais, periodicamente, variáveis entre elas, a cada vinte e um dias, uma vez ao mês e de três em três meses, até a negativação dos exames. A seguir o paciente é reavaliado a cada seis meses. São realizados exames de função renal, hepática e hemograma completo em todas as clínicas. A pesquisa parasitológica é realizada somente em três clínicas, para controle dos animais em tratamento.

\section{CONCLUSÃO}

Havendo condições clinicas suficientes, comprometimento do proprietário e conhecimento sobre a enfermidade, bem como de acordo com o estado geral doanimal,ele pode ser submetido a tratamento experimental. No presente estudo a taxa de sucesso quanto a melhora clínica, e recuperação do estado geral do animal, foi de $66,9 \%$.

Antimoniais pentavalentes e a anfotericina B, medicamentos de uso comum ao tratamento humano, são utilizadas em clínicas de Brasilia, apesar da proibição. Ainda existem clínicas realizando tratamentos de forma inadequada, porém a maioria utiliza protocolo de tratamento com outros medicamentos, como o alopurinol.

Os proprietários são selecionados de acordo com comprometimento e responsabilidade, condição socioeconômica e presença nas consultas periódicas, o que possibilita a realização de tratamento de maneira contínua e consciente.

A maioria das clínicas de pequenos animais de Brasília, que responderam ao questionário opta pelo tratamento, sendo o medicamento mais utilizado o alopurinol, entretanto, são utilizados antimoniais pentavalentes, anfotericina B, domperidona, ciprofloxacina, marbofloxacina e miltefosina. Por outro lado, há clínicas que optam pela eutanásia e algumas não querem discutir a possibilidade de tratamento da LVC.

ANEXO 1 : Questionário para obtenção de informações

Albuquerque ALH, Langoni H. A prática do tratamento na Leishmaniose visceral canina (LVC) em clínicas veterinárias, cuidados e protocolos. Vet. e Zootec. 2018 jun.; 25(1): 132-141. 


\section{Casuística:}

Quantos animais infectados foram atendidos?

Quantos foram tratados?

Quantos foram tratados (sem resposta) e eutanasiados?

Quantos foram eutanasiados, sem tratamento?

\section{Qual(is) os métodos diagnósticos laboratoriais utilizados?}

Citologia por escarificação de lesão, citologia por punção aspirativa, impressão por aposição ou biópsia de lesões cutâneas ou órgãos linfáticos, citologia, histopatológico, isolamento do Parasita em meios específicos ou Hamsters, PCR, RIFI ou ELISA

3. Caso seja realizado tratamento, qual o tratamento de escolha?

Alopurinol, anfotericina B, antimoniais pentavalentes (antimoniato de N-metil-glucamina ou estibogluconato de Sódio), marbofloxacina, aminosidina, miltefosina e tratamento suporte de acordo com a necessidade de cada animal (fluidoterapia, vitaminas) ou outro (especifique)

\section{São recomendadas como ações preventivas? Quais?}

Utilização de coleira de repelente, inseticidas, telagem de janelas e vacinação de animais contactantes

5. Caso seja realizada vacinação dos animais, qual a de escolha?

Leishmune $\AA$, Leish-tec $®$ ou outra (especifique)

6. Em relação ao proprietário, há seleção dos mesmos de acordo com seu nível socioeconômico para realizar tratamento?

SIM NÃO

7. Há seleção dos proprietários de acordo com sua responsabilidade e presença nas consultas?

SIM NÃO

8. Em relação aos animais infectados, são realizadas consultas periódicas dos animais em tratamento?

SIM NÃO

9. Se sim, com que frequência?

10. Se sim, são realizados exames laboratoriais de acompanhamento?

$\square$ Sim, função renal $\square$ Sim, função hepática $\square$ Sim, hemograma completo, $\square$ Sim, pesquisa parasitológica $\square$ Não

\section{REFERÊNCIAS}

1. Ferreira EC, De Melo LA, Gontijo CMF. Leishmanioses do novo mundo. Cad Tec Vet Zootec. 2012;65:9-27.

2. Lappin MR. Leishmaniose. In: Nelson RW, Couto CG. Medicina interna de pequenos animais. 4a ed. St. Louis: Elsevier; 2010. p.1364-5. 
3. Greene CE. Infectious diseases of the dog and cat. 4a ed. St Louis: Saunders Elsevier; 2011.

4. Pirajá GV, Lucheis SB. A vigilância epidemiológica de flebotomíneos no planejamento de ações de controle nas leishmanioses. Vet Zootec. 2014;21:503-15.

5. Duprey ZH, Steurer FJ, Rooney JA. Canine visceral leishmaniasis, United States and Canada, 2000-2003. Emerg Infect Dis. 2006;12:440-6.

6. Freitas E, Melo MN, Costa-Val AP, Michalick MS. Transmission of Leishmania infantum via blood transfusion in dogs: potential for infection and importance of clinical factors. Vet Parasitol. 2006;137:159-67.

7. Camargo JB, Troncarelli MZ, Ribeiro MG, Langoni H. Leishmaniose visceral canina: aspectos de saúde pública e controle. Clin Vet. 2007;71:86-92.

8. Ministério da Saúde (BR). Secretaria de Vigilância em Saúde. Departamento de Vigilância Epidemiológica. Guia de vigilância epidemiológica. 6a ed. Brasília: Ministério da Saúde; 2006.

9. Camargo JB, Langoni H, Troncarelli MZ, Machado JG, Lucheis SB, Padovani CR. Performance of IFAT, ELISA, direct parasitological examination and PCR on lymphonode aspirates of canine visceral leishmaniosis diagnosis. J Venom Anim Toxins Incl Trop Dis. 2010;16:414-20.

10. Langoni H, Lucheis SB, Silva RC, Castro APB, Pas AC. American visceral leishmaniasis: a case report. J Venom Anim Toxins Incl Trop Dis. 2005;11:360-71.

11. Donato LE, Lima Júnior FEF, Albuquerque R, Gomes MLS. Vigilância e controle de reservatórios da leishmaniose visceral no Brasil: aspectos técnicos e jurídicos. Rev Educ Contin Med Vet Zootec CRMV-SP. 2013;11:18-23.

12. Volkweis F, Cavalcanti L, Biazio G, Molinari F. Prevalência de Leishmania spp. em cães no Distrito Federal, utilizando a técnica de PCR. In: Anais do Congresso Medvet de Especialidades Veterinárias; 2013; Bento Gonçalves. Bento Gonçalves: Medvet; 2013.

13. Tamayo C, Carvalho M, Bofil M, Rodrigues R, Silva A, Cortez S, et al. Leishmaniose visceral autóctone em Brasília, Distrito Federal, Brasil. Rev Soc Bras Med Trop. 2010;43(4):396-9.

14. Denerolle P. Leishmaniose canine : difficultés du diagnostic et du traitement (125 cas). Prat Med Chir Anim Comp. 1996;31(2):137-5.

15. Ginel PJ, Lucena R, López R, Molleda JM. Use of allopurinol for maintenance of remission in dogs with leishmaniasis. J Small Anim Pract. 1998;39 (6):271-4.

16. Moura S, Fernandes C, Pandulho V, Rodrigues, Silva R. Diagnóstico de leishmaniose canina na área urbana do município de Cuaiabá, estado do Mato Grosso, Brasil. Braz J Vet Res Anim Sci. 1999;36(2):123-6.

17. Petersen CA, Barr SC. Canine leishmaniasis in North America: emerging or newly recognized? Vet Clin North Am Small Anim Pract. 2009;39(6):1065-74.

18. Monteiro JM, Seguro AC, Rocha AS. Nefrotoxicidade aguda da anfotericina b no cão. Rev Hosp Clin Fac Med Sao Paulo. 1992;48(2):54-9.

19. Tavares W. Poliênicos e outros antibióticos antifúngicos. In: Tavares W. Manual de antibióticos. 3a ed. São Paulo: Atheneu; 2002. p.747-64. 
20. Nogueira FS. Avaliação clínico-laboratorial de cães naturalmente infectados por Leishmaniose visceral, submetidos à terapia com anfotericina B [tese]. Botucatu: Faculdade de Medicina Veterinária e Zootecnia, Universidade Estadual Paulista; 2007.

21. Tempone AG, Andrade Jr HF. Nanoformulações de antimônio pentavalente encapsuladas em lipossomos contendo fosfatidilserina demonstram maior eficácia contra Leishmaniose Visceral experimental. Rev Inst Adolfo Lutz. 2008;67(2):131-6.

22. Vouldoukis I, Rougier S, Dugas B, Pino P, Mazier D, Woehrlé F. Canine visceral leishmaniasis: comparison of in vitro leishmanicidal activity of marbofloxacin, meglumine antimoniate and sodium stibogluconate.Vet Parasitol. 2006;135(2):137-46.

23. Gómez Ochoa P. Estudio de un nuevo tratamiento de la leishmaniosis canina. Valoración del efecto inmunomodulador de la domperidona [tese]. Zaragoza: Facultad de Veterinaria, Universidad de Zaragoza; 2004.

24. Ai H, Awad A, Moker HM. Evaluation of intralesional 0,2\% ciprofloxacin as a treatment for cutaneous leishmaniasis. East Mediterr Health J. 2010;16(1):89-93.

25. Noli C. Leishmaniosis canina. Waltham Focus. 1999;9(2):16-24.

26. Guerra MER. Prospecção de novos peptídeos com ação leishmanicida por dinâmica molecular [dissertação]. São José do Rio Preto: Universidade Estadual Paulista; 2014.

27. Vila-Nova N, Morais S, Falcão M, Bevilaqua C, Rondon F, Wilson M, et al. Atividade inibitória leishmanicida e colinesterásica de compostos fenólicos de Dimorphandra gardneriana e Platymiscium fliribunbum, plantas nativas do bioma Caatinga. Pesqui Vet Bras. 2012;32(11):1164-8.

28. Tempone AG. Secreção cutânea do caramujo gigante africano, Achatina fulica, como fonte de compostos anti-Leishmania. Rev Inst Adolfo Lutz. 2007;66(1):73-7.

29. Gradoni L, Gramiccia M, Mancianti F, Pieri S. Studies on leishmaniasis control: effectiveness of control measures against canine leishmaniasis in the island of Elba, Italy. Trans R Soc Trop Med Hyg.1998;82(3):568-71.

30. Foglia Manzillo V, Oliva G, Pagano A, Manna L, Maroli M, Gradoni L. Deltamethrinimpregnated collars for the control of canine leishmaniasis: Evaluation of the protective effect and influence on the clinical outcome of Leishmania infection in kennelled stray dogs. Vet Parasitol 2006;142(1-2):142-5.

31. Langoni H. Leishmaniasis. In: Megid J, Ribeiro MG, Paes AC. Doenças infecciosas em animais de produção e companhia. 1a ed. Rio de Janeiro: Roca; 2016. p.1013-24.

32. Ministério da Saúde. Departamento de Vigilância das Doenças Transmissíveis. Esclarecimento sobre substituição do protocolo diagnóstico da leishmaniose visceral canina (LVC). Brasília: Ministério da Saúde; 2011.

Recebido em:

Aceito em: 